\title{
Effect of age and sex on warfarin dosing
}

This article was published in the following Dove Press journal:

Clinical Pharmacology: Advances and Applications

12 July 2014

Number of times this article has been viewed

\author{
Ghada Khoury' \\ Marwan Sheikh-Taha ${ }^{2}$ \\ 'School of Pharmacy, ${ }^{2}$ Department \\ of Pharmacy Practice, Lebanese \\ American University, Byblos, \\ Lebanon
}

Correspondence: Marwan Sheikh-Taha Department of Pharmacy Practice, Lebanese American University, PO Box 36, Byblos, Lebanon Fax +I 80I 76I 2883

Email marwan.taha@lau.edu.lb
Objective: We examined the potential effect of sex and age on warfarin dosing in ambulatory adult patients.

Methods: We conducted a retrospective chart review of patients attending an anticoagulation clinic. We included patients anticoagulated with warfarin for atrial fibrillation or venous thromboembolism who had a therapeutic international normalized ratio of 2-3 for 2 consecutive months. We excluded patients who had been on any drug that is known to have a major interaction with warfarin, smokers, and heavy alcohol consumers. Out of 340 screened medical records, 96 met the predetermined inclusion criteria. The primary outcome assessed was warfarin total weekly dose (TWD).

Results: There was a statistically significant difference in the TWD among the ages $(P<0.01)$; older patients required lower doses. However there was no statistically significant difference in the TWD between sexes $(P=0.281)$.

Conclusion: Age was found to have a significant effect on warfarin dosing. Even though women did require a lower TWD than men, this observation was not statistically significant.

Keywords: warfarin, INR, anticoagulation, vitamin K antagonists, age

\section{Introduction}

Until recently, warfarin had been one of the only treatment options for long-term anticoagulation of patients requiring chronic oral anticoagulation. In the last few years, a number of new oral anticoagulant agents, dabigatran, rivaroxaban, apixaban, and edoxaban, have been studied and approved for prevention of stroke in non-valvular atrial fibrillation (AF) and treatment or prevention of venous thromboembolism (VTE). However, many unresolved questions remain on how to optimally use these drugs in specific clinical situations such as those with chronic kidney disease and hepatic insufficiency, and in those taking drugs that can inhibit cytochrome P450 (CYP)-3A4. Furthermore, practical concerns have been raised about the lack of a reversal agent for any of these three new agents. Consequently, warfarin will likely remain an important therapeutic option for the primary and secondary prevention of thromboembolic events for a variety of medical conditions for many patients. ${ }^{1,2}$ Warfarin works by inhibiting the synthesis of vitamin-K dependent clotting factors II, VII, IX, and X as well as the anticoagulant factors, proteins $\mathrm{C}$ and $\mathrm{S}$. It is a difficult drug to dose because many factors are incompletely understood that influence an individual's response. ${ }^{1,2}$ It is also a complex drug because of its narrow therapeutic window, with even a mild degree of over-anticoagulation potentially leading to hemorrhagic complications. ${ }^{3}$ These limitations necessitate the close monitoring of the international normalized ratio (INR), which is both resource intensive and inconvenient. Warfarin's pronounced 
inter-individual variability in dose requirements and its complicated management has led to numerous studies evaluating different potential predictors of warfarin requirements, including age, sex, nutritional status, presence of comorbid conditions, concomitant medications, and vitamin $\mathrm{K}$ intake. ${ }^{2,4}$ The objective of our study was to examine the potential effect of age and sex on warfarin maintenance dose in ambulatory adult patients.

\section{Methods}

We conducted a retrospective study at a long-term outpatient anticoagulation clinic (Celebration Health, Florida Hospital). The clinic uses point-of-care monitoring. At the clinic, patients are scheduled for 20 minute office visits during which an instant finger-stick INR is obtained using CoaguChek S (Hoffman-La Roche Ltd, Basel, Switzerland). Patients are also asked about factors that might affect their INR or warfarin dosing. The clinical pharmacists subsequently provide the patient with dosing instructions and may renew prescriptions for warfarin and low-molecular-weight heparins on behalf of the patients' enrolling physicians, as part of a collaborative-practice agreement. Patients leave each visit with their instant INR results, dosing regimen, and next scheduled follow-up appointment.

The medical records of all patients actively enrolled at the clinic from 2007-2009 were randomly selected for review. Inclusion criteria were patients with AF or VTE on warfarin with an INR range of 2-3; patients stabilized on warfarin therapy (reflected by two consecutive therapeutic INR at the same total weekly dose [TWD]); non-smokers; patients with no to moderate alcohol consumption ( $\leq 2$ drinks per day). To control for confounders, we excluded patients who were anticoagulated for other indications, smokers, heavy alcohol consumers (more than two drinks per day), and patients on drugs with major interactions with warfarin as identified by the Drug Information Handbook (17th edition). ${ }^{5}$

The TWD of warfarin was calculated for each patient. The following data were also collected: indication for warfarin, sex, age (divided into eight groups; group one: 20-29 years, group two: 30-39 years, group three: 40-49 years, group four: 50-59 years, group five: 60-69 years, group six: 70-79 years, group seven: 80-89 years, group eight: 90 years or above), alcohol consumption, and the patient's medication list (including prescription and over the counter medications).

The primary outcome was the warfarin TWD. To detect a possible difference in the TWD between the sexes, we used the Student's $t$-test. To assess the impact of age, we used analysis of variance (ANOVA) followed by a Bonferroni post hoc test.
Data analysis was performed using SPSS for windows version 15.0 (SPSS Inc., Chicago, IL, USA) with the a priori level of significance set at a $P$-value of 0.05 or less.

\section{Results}

A review of 340 medical records was concluded, of which 96 patients met the inclusion criteria. Baseline characteristics are summarized in Table 1. The mean TWD (mg) \pm standard deviation (SD) was $39.44 \pm 14.21$ for men and $36.15 \pm 15.43$ for women $(P=0.281)$ as shown in Table 2. The mean TWD was trending downward as age increased. A statistically significant lower mean TWD was seen in patients in the 80-89 age group as compared to patients in 20-29, 30-39, 40-49, and 50-59 age groups $(P<0.05)$. Mean TWD of patients in group 20-29, 30-39, and 40-49 was around $51 \mathrm{mg}$ as compared to almost half, $24.82 \mathrm{mg}$, in group $80-89(P<0.05)$ as shown in Table 3 .

\section{Discussion}

Warfarin therapy remains challenging. When initiated, it is associated with either a high incidence of overanticoagulation which leads to bleeding or persistent subtherapeutic INR that not only prolongs the period of thrombotic risk, but potentially increases costs because of subsequent adjunctive use of other parenteral anticoagulants. It is hard to make accurate dose prediction due to the inability to take inter-individual and intraindividual variability in response to the drug into account. This is frequently a cause for concern.

Table I Baseline characteristics

\begin{tabular}{lll}
\hline \multicolumn{1}{l}{ N } & Percentage \\
\hline Indication & & \\
AF & 45 & $47 \%$ \\
VTE & 51 & $53 \%$ \\
Sex & 54 & $56 \%$ \\
Men & 42 & $44 \%$ \\
Women & & \\
Age & 3 & $3 \%$ \\
Group I (20-29) & 3 & $3 \%$ \\
Group 2 (30-39) & 10 & $10 \%$ \\
Group 3 (40-49) & 18 & $19 \%$ \\
Group 4 (50-59) & 22 & $23 \%$ \\
Group 5 (60-69) & 24 & $25 \%$ \\
Group 6 (70-79) & 14 & $15 \%$ \\
Group 7 (80-89) & 2 & $2 \%$ \\
Group 8 ( $\geq 90)$ & & $86 \%$ \\
Alcohol intake & 83 & $14 \%$ \\
None/occasional & 13 & \\
I-2 drinks/day & & \\
\hline
\end{tabular}

Abbreviations: $\mathrm{N}$, number of patients; AF, atrial fibrillation; VTE, venous thromboembolism. 
Table 2 Warfarin TWD based on sex

\begin{tabular}{lll}
\hline & Mean TWD $(\mathbf{m g}) \pm$ SD & $P$-value \\
\hline Men & $39.44 \pm \mid 4.211$ & $P=0.28 \mid$ \\
Women & $36.15 \pm \mid 5.433$ & \\
\hline
\end{tabular}

Abbreviations: TWD, total weekly dose; SD, standard deviation.

The present study found a significant association between increasing age and a reduced maintenance dosage of warfarin. The TWD for patients $80-89$ years of age was $24.82 \mathrm{mg}$, which was almost half the TWD for groups aged between 20-59 years (mean TWD for the four age groups $=49.18 \mathrm{mg}$ ). A simple clinical approach to starting warfarin therapy in patients between ages 80-89 without an acute event would be to initiate daily doses reflective of $25 \mathrm{mg}$ per week. These findings confirm previously published literature; warfarin dose for maintenance therapy is inversely proportional to age. ${ }^{6-12}$ Patients $\geq 90$ years (group eight) received a TWD that was lower than groups one, two, three, four, and five $(28.5 \mathrm{mg}$ versus an average of $49.18 \mathrm{mg}$ ) but this difference was not statistically significant. This may be explained by the small number of patients in group eight (only two patients).

Our study adds to the body of evidence supporting warfarin dosing adjustments in the elderly. Data published by Garcia et al suggested that as patients age, the TWD declines by $0.4 \mathrm{mg}$ per year of life. ${ }^{13}$ The mechanism for increased sensitivity to warfarin with aging is not well-understood. In general, the elderly have decreased serum proteins, metabolic activities, and renal excretion. ${ }^{14}$ These alterations lead to differences in the pharmacokinetics of a drug that increases the persistence of the drug in the body, and consequently, increased sensitivity to the drug is observed among the elderly. However, a previous report has revealed that there was no appreciable difference in the pharmacokinetics of warfarin, ie, the plasma half-life, apparent volume of distribution, plasma clearance, and plasma warfarin metabolite levels,

Table 3 Warfarin TWD based on age

\begin{tabular}{lll}
\hline & $\mathbf{N}$ & Mean TWD \pm SD $(\mathbf{m g})$ \\
\hline Group I (20-29) & 3 & $51.67 \pm 7.638$ \\
Group 2 (30-39) & 3 & $50.83 \pm 23.761$ \\
Group 3 (40-49) & 10 & $50.75 \pm 20.852$ \\
Group 4 (50-59) & 18 & $43.50 \pm 12.332$ \\
Group 5 (60-69) & 22 & $36.05 \pm 11.219$ \\
Group 6 (70-79) & 24 & $35.54 \pm 11.794$ \\
Group 7 (80-89) & 14 & $* 24.82 \pm 8.363$ \\
Group 8 ( $\geq 90)$ & 2 & $28.50 \pm 12.728$ \\
Total & 96 & $38.01 \pm 14.770$ \\
\hline
\end{tabular}

Note: *Total weekly dose in group seven significantly lower than that in groups one, two, three, and four $(P<0.05)$.

Abbreviations: TWD, total weekly dose; SD, standard deviation. between younger (age range 20-40; mean, 25 years) and older (age range, 65-94; mean, 82 years) patients. ${ }^{15}$ This suggests that pharmacokinetic factors did not influence the age-dependent increase in the sensitivity to warfarin. Pharmacodynamic changes with age have been much less studied. A negative correlation between age and hepatic drug-metabolizing enzymes has been detected in rat models in vitro, and a study of hepatic microsomal enzymes in humans showed a $30 \%$ decline in hepatic drug metabolism and cytochrome $\mathrm{P} 450$ content with age. ${ }^{16-18}$ Others have suggested an age-related decrease in the diffusion of oxygen within the hepatocyte that compromises the oxygen-dependent mixedfunction oxidase enzymes. ${ }^{19}$ Changes in hepatic glutathione levels and decreased activity of the nicotinamide adenine dinucleotide phosphate-dependent reductase of vitamin $\mathrm{K}$ are other postulated hypotheses. ${ }^{20}$

Several studies, ${ }^{7,10,21}$ but not all, ${ }^{8,22-24}$ report that sex is a determinant of warfarin dose; women require lower doses than men. However, in our study, although women required a $3.29 \mathrm{mg}$ lower TWD than men, the difference was not statistically significant.

Because all patients were managed in the same anticoagulation clinic with the same anticoagulation monitor, the variability resulting from different management strategies and testing methods was controlled.

The present study has several limitations. All information collected was via retrospective chart review. We only included outpatients from a single tertiary care center. We had a relatively small sample size, which means that this study may not have been adequately powered to detect a statistically significant difference between patient-specific factors, if a true difference did exist. It was not feasible to control for all confounders, they were limited to the extent possible by excluding smokers, heavy alcohol consumers, and patients on any drug that interacts extensively with warfarin. Although we attempted to account for as many confounding factors as possible we did not gather information on the patients' diet, compliance with anticoagulant drug therapy, and changes in health status. However, since our data were from stable patients, and since the INRs did not vary, we do not believe that any changes in these variables were significant enough to affect anticoagulation control.

The accuracy of our study would have been improved by the inclusion of information on genetic polymorphisms since polymorphisms of the vitamin $K$ epoxide reductase complex subunit 1 gene (VKORC1) and the CYP2C9 gene are important determinants of warfarin dosing. We did not include information on genetic polymorphism due to the 
difficulty and the questionable utility of performing genetic evaluation in the clinical setting. Many clinicians believe that a genetic-based dosing scheme is unlikely to result in a practical advantage because of several reasons, including timely access to genotyping, which might result in unnecessary treatment delays and subsequent prolongation of the parenteral anticoagulation, increased costs, and inability of genetic-based models to account for environmental factors. Furthermore, dosing adjustments continue to be based on INR values that could be considered a surrogate marker of genetic information.

\section{Conclusion}

This study found that mean warfarin doses declined predictably with age and were not affected by sex. Although it did appear that women required a smaller TWD than men, the difference was not statistically significant. These observations suggest that the current initiation and maintenance doses should be modified to reduce the risk of inadequate therapy in young patients and excessive anticoagulation in the elderly.

\section{Disclosure}

The authors have no conflicts of interest to declare.

\section{References}

1. Ansell J, Hirsh J, Hylek E, Jacobson A, Crowther M, Palareti G. Pharmacology and Management of the Vitamin K Antagonists: American College of Chest Physicians Evidence-Based Clinical Practice Guidelines. 8th ed. Chest. 2008;133(Suppl 6):160S-198S.

2. James AH, Britt RP, Raskino CL, Thompson SG. Factors affecting the maintenance dose of warfarin. J Clin Pathol. 1992;45(8): 704-706.

3. White P. Patient factors that influence warfarin dose response. J Pharm Pract. 2010;23(3):194-204.

4. Hamberg AK, Wadelius M, Lindh JD, et al. A pharmacometric model describing the relationship between warfarin dose and INR response with respect to variations in CYP 2C9, VKORC1, and age. Clin Pharmacol Ther. 2010;87(6):727-734.

5. Lacy CF, Armstrong LL, Goldman MP, Lance LL. Drug Information Handbook. 17th ed. Hudson: Lexi-Comp, Inc.; 2008.

6. Singla DL, Morrill GB. Warfarin maintenance dosages in the very elderly. Am J Health Syst Pharm. 2005;62(10):1062-1066.
7. Absher RK, Moore ME, Parker MH. Patient-specific factors predictive of warfarin dosage requirements. Ann Pharmacother. 2002;36(10): 1512-1517.

8. Whitley HP, Fermo JD, Chumney EC, Brzezinski WA. Effect of patient-specific factors on weekly warfarin dose. Ther Clin Risk Manag. 2007;3(3):499-504.

9. Gage BF, Eby C, Milligan PE, Banet GA, Duncan JR, McLeod HL. Use of pharmacogenetics and clinical factors to predict the maintenance dose of warfarin. Thromb Haemost. 2004;91(1):87-94.

10. Gan GG, Teh A, Goh KY, Chong HT, Pang KW. Racial background is a determinant factor in the maintenance dosage of warfarin. Int $J$ Hematol. 2003;78(1):84-86.

11. Gurwitz JH, Avorn J, Ross-Degnan D, Choodnovskiy I, Ansell J. Aging and the anticoagulant response to warfarin therapy. Ann Intern Med. 1992;116(11):901-904.

12. Merli GJ. Prevention of thrombosis with warfarin, aspirin, and mechanical methods. Clin Cornerstone. 2005;7(4):49-56.

13. Garcia D, Regan S, Crowther M, Hughes RA, Hylek EM. Warfarin maintenance dosing patterns in clinical practice: implications for safer anticoagulation in the elderly population. Chest. 2005;127(6):2049-2056.

14. Crooks J, O'Malley K, Stevenson IH. Pharmacokinetics in the elderly. Clin Pharmacokinet. 1976;1(4):280-296.

15. Shepherd AM, Hewick DS, Moreland TA, Stevenson IH. Age as a determinant of sensitivity to warfarin. Br J Clin Pharmacol. 1977;4(3): $315-320$.

16. Woodhouse $\mathrm{KW}$, James OF. Hepatic drug metabolism and ageing. Br Med Bull. 1990;46(1):22-35.

17. Schmucker DL. Aging and the liver: an update. J Gerontol A Biol Sci Med Sci. 1998;53(5):B315-B320.

18. Le Couteur DG, McLean AJ. The aging liver. Drug clearance and oxygen diffusion barrier hypothesis. Clin Pharmacokinet. 1998;34(5): 359-373.

19. Loguercio C, Taranto D, Vitale LM, Beneduce F, Del Vecchio Blanco C. Effect of liver cirrhosis and age on the glutathione concentration in the plasma, erythrocytes, and gastric mucosa of man. Free Radic Biol Med. 1996;20(3):483-488.

20. Sotaniemi EA, Arranto AJ, Pelkonen O, Pasanen M. Age and cytochrome P450-linked drug metabolism in humans: an analysis of 226 subjects with equal histopathologic conditions. Clin Pharmacol Ther. 1997;61(3):331-339.

21. Casner PR, Sandoval E. Increased sensitivity to warfarin in elderly Hispanics. J Clin Pharmacol. 2002;42(2):145-150.

22. Borgiani P, Ciccacci C, Forte V, Romano S, Federici G, Novelli G. Allelic variants in the CYP2V9 and VKORC1 loci and interindividual variability in the anticoagulant dose effect of warfarin in Italians. Pharmacogenomics. 2007;8(11):1545-1550.

23. Cho HJ, Sohn KH, Park HM, et al. Factors affecting the interindividual variability of warfarin dose requirements in adult Korean patients. Pharmacogenomics. 2007;8(4):329-337.

24. Yoo SH, Nah HW, Jo MW, et al. Age and body weight adjusted warfarin initiation program for ischaemic stroke patients. Eur J Neurol. 2009;16(10):1100-1105.
Clinical Pharmacology: Advances and Applications

\section{Publish your work in this journal}

Clinical Pharmacology: Advances and Applications is an international, peer-reviewed, open access journal publishing original research, reports, reviews and commentaries on all areas of drug experience in humans. The manuscript management system is completely online and includes a very quick and fair peer-review system, which is all easy to use.

\section{Dovepress}

Visit http://www.dovepress.com/testimonials.php to read real quotes from published authors. 